\title{
Cuando la ciencia se adorna de colores
}

\begin{abstract}
A. Cano, M.I. La Torre, C. Monsalve, J. Roque, W. Mendoza, I. Salinas, S. Castillo y H. Aponte. 2005. Las Plantas Comunes de San Marcos (Huari, Ancash). Guía de Campo. 147 pp. Serie de Divulgación No. 12, Museo de Historia Natural de la Universidad Nacional Mayor de San Marcos. ISSN: 1015-1605.
\end{abstract}

Me parece no tener ojos suficientes para verlo todo

Antonio Raimondi

La conservación de la biodiversidad ha dejado de ser un tema de discusión únicamente en círculos científicos e intelectuales, para convertirse en un tema de noticia diaria. Esto ha llevado entre otras cosas a la creación de instrumentos de información para todos los agentes sociales de las áreas geográficas donde se pretende establecer proyectos de explotación de recursos, en particular para las comunidades campesinas e indígenas.

La única manera de apreciar y valorar un recurso es conociéndolo, a pesar de ello la información de nuestra mayor riqueza, la biodiversidad, sólo se ha venido restringiendo a las comunicaciones especializadas que circulan en la comunidad científica, dejando de lado a los agentes sociales y políticos de los cuales dependen las decisiones sobre la explotación sustentable de los recursos. Es por esto que publicaciones como la comentada aquí tienen mucha importancia, porque teniendo como principal objetivo la divulgación, no dejan de ser importante fuente de información y herramienta de trabajo para futuros estudios, así como información básica para proyectos de manejo de recursos naturales y ecoturismo.

La flora de Ancash ha sido estudiada de manera esporádica, con los trabajos de Weberbauer (1945), Cerrate (1979), Smith (1988), Arana \& Salinas (2003), Monsalve \& Cano (2003) entre otros, aunque el antecedente más cercano del trabajo comentado aquí es la publicación de Kolff \& Kolff(1997) «Flores silvestres de la cordillera Blanca», donde presentan fotos de 100 especies de plantas, principalmente del Parque Nacional Huascarán,
Ancash. En comparación a este último antecedente, el trabajo de Asunción Cano y colaboradores en la mayoría de casos presenta una mejor calidad en las fotografías, además la información ofrecida sobre las especies es más amplia, en especial acerca de la distribución geográfica de las mismas. Adicionalmente, el prestigio del autor principal como botánico y su filiación al Herbario San Marcos (USM), asegura una identificación válida de las especies y la presencia de vouchers que la respaldan.

Otros antecedentes son los trabajos de recopilación fotográfica de especies de flora en las Guías del proyecto de Rapid Color Guides del Field Museum of Natural History of Chicago (http://fm2.fieldmuseum.org/ plantguides/rcg_intro.asp), aunque en estas sólo se encuentra el nombre de las especie sin ninguna otra información adicional.

La publicación de Cano y colaboradores carece de algunos elementos que la mejorarían. Por ejemplo es notorio la falta de un índice de las especies consideradas, así como un sistema que facilite más su búsqueda para el lector no especialista (el orden por familia botánica es adecuado sólo para especialistas en flora). También carece de las referencias bibliográficas indicadas en su texto, así como de un mapa de ubicación del área de estudio. Otras deficiencias menores son la falta de una explicación clara sobre el criterio de selección de las especies mostradas, el no mencionar el sistema de clasificación taxonómica utilizado, la falta de consistencia en el uso de puntos o comas decimales y la ausencia en el glosario de términos técnicos incluidos en el texto 
(como saxícola o savia). Otros errores editoriales como el no incluir en la carátula interior el ISSN u omitir el título Descripción de las especies también fueron encontrados.

Más allá de estas observaciones, esta Guía de Campo es una herramienta útil para botánicos que inician su trabajo en los Andes, para los docentes de cursos sobre florística andina, así como para especialistas de diferentes ramas de la Biología, como Ecólogos, Zoólogos, Fisiólogos interesados en la biota andina, en especial del departamento de Ancash. Es también una publicación de consulta indispensable para proyectos de desarrollo sustentable y ecoturismo de la zona.

Por último, expreso mi felicitación a los autores y estamos en espera de futuras contribuciones sobre las plantas andinas que conforman una de las más intrigantes y particulares floras del Mundo, y también esperamos ansiosos poder recrear nuestra vista con las hermosas flores que colorean la ciencia.

\section{Literatura citada}

Arana, C. y L. Salinas. 2003. Flora vascular de los humedales de Chimbote, Perú. Revista Peruana de Biología 10(2): 221-224

Cano, A., M.I. La Torre, C. Monsalve, J. Roque, W. Mendoza, I. Salinas, S. Castillo y H. Aponte. 2005. Las Plantas Comunes de San Marcos (Huari, Ancash). Guía de Campo. 147 pp. Serie de Divulgación No. 12, Museo de Historia Natural de la Universidad Nacional Mayor de San Marcos.

Cerrate, E. 1979. Vegetación del Valle de Chiquián, Provincia Bolognesi, Departamento de Ancash. 65 pp. Edit. Los Pinos, Lima.

Kolff, H. y A. Kolff. 1997. Flores silvestres de la Cordillera Blanca. 284 pp. Instituto de Montaña, Lima.

Monsalve, Ch. \& A. Cano. 2003. La Familia Brassicaceae en la Provincia de Huaylash, Ancash. Revista Peruana de Biología 10(1):20-32.

Smith, D. 1988. Flora and Vegetation of the Huascaran National Park, Ancash, Peru; with preliminary studies for a manual of the flora. Thesis to obtain the degree of Doctor of of Philosophy. Iowa State University, Ames, Iowa.

Weberbauer, A. 1945. El Mundo Vegetal de los Andes Peruanos. 776 pp. Ministerio de Agricultura, Lima.

\section{César Arana}

Museo de Historia Natural y

Facultad de Ciencias Biológicas,

Universidad Nacional Mayor de San Marcos

Avenida Arenales 1256, Apartado 14-0434, Lima 14, Perú 